University for Business and Technology in Kosovo

UBT Knowledge Center

UBT International Conference

2018 UBT International Conference

Oct 27th, $10: 45$ AM - 12:15 PM

\title{
Evaluation of the Appearance of Dermatological Bullous Diseases in the Oral Cavity
}

Ilma Robo

Albanian University, Tirana, ilmarobo@yahoo.com

Vera Ostreni

Albanian University, Tirana

Eriola Meta

Albanian University, Tirana

Alert Xhaja

University Medical Center of Tirana "Mother Teresa"

Saimir Heta

University Medical Center of Tirana "Mother Teresa"

Follow this and additional works at: https://knowledgecenter.ubt-uni.net/conference

Part of the Medicine and Health Sciences Commons

\section{Recommended Citation}

Robo, Ilma; Ostreni, Vera; Meta, Eriola; Xhaja, Alert; and Heta, Saimir, "Evaluation of the Appearance of Dermatological Bullous Diseases in the Oral Cavity" (2018). UBT International Conference. 359.

https://knowledgecenter.ubt-uni.net/conference/2018/all-events/359

This Event is brought to you for free and open access by the Publication and Journals at UBT Knowledge Center. It has been accepted for inclusion in UBT International Conference by an authorized administrator of UBT Knowledge Center. For more information, please contact knowledge.center@ubt-uni.net. 


\title{
Topic: Evaluation of the appearance of dermatological bullous diseases in the oral cavity
}

\author{
M.D. Ilma Robo, ${ }^{1}$ Prof.Dr. Vera Ostreni, ${ }^{1}$ Msc. Eriola Meta, ${ }^{1}$ Dr. Alert Xhaja, ${ }^{2}$ PhD. Saimir Heta ${ }^{3}$ \\ ${ }^{1}$ Albanian University, Department of Stomatology, Tirana, Albania \\ ${ }^{2}$ Department of Dermatology, QSUT, Tirana, Albania \\ ${ }^{3}$ Department of Pediatric Surgery, QSUT, Tirana, Albania \\ email: ilmarobo@yahoo.com
}

\begin{abstract}
Introduction: Dermatological bullous diseases have visible signs in the oral cavity. The study is aimed at early detection of oral lesions, to link them to the presence or not of apparent skin disorders affecting the quality of the patient's lifestyle. Patient awareness of coexistence between dermatological concerns and the presence of oral lesions should be the starting point of every dentist during the intraoral examination, after drying of the mucous membranes and gingiva.

Materials and methods: The study includes patients randomly presented: patients at the University Clinic AU and patients in the Dermatology Department, QSUT, during the period between november 2017 and january 2018. Patients were evaluated according to the Dermatological Life Quality Index (ICJD) and the presence of oral lesions in the oral cavity.

Results: Oral lesions reported in the patients appear to be more commonly occurring in female patients than in male patients over 40 years of age. Oral buccal mucosa areas are more affected than gingival area, palatum and tongue areas.

Conclusions: Detection of disorders during oral routine examination is the beginning to follow the evolution of these dermatological bullous diseases, as the further prognosis also depends on the moment of detection and awareness of the initial existence of the disease.
\end{abstract}

Keywords: ICJD, bullous diseases, oral mucous membranes, gingiva

\section{Introduction}

Patients affected by bullous diseases are divided into two categories, those who are pre-diagnosed and wellinformed of the presence of the disease, and those who do not know the presence of the disease. In the last group, their first contact for more information is the dentist who checks, examines and evaluates the presence of "wounds" in the mouth. The challenge in this process is the duplication of primary lesions in secondary lesions, which are undiagnosed, and which still make the clinical appearance of the patient more difficult. ${ }^{(1)}$ The other purpose of this study consisted in sensitizing the diagnosis of desquamative gingivitis, about the connection of its existence with the presence of a non-expressed immunological disease with a clinical appearance in the skin. Desquamative gingivitis is a symptom treated by dental practitioners, but the agitation and allinclusivity from the later disease of the organism causes the patient to pass the dermatologist for further, hospitalized treatment. Sensitization about this pathology makes dental practitioners more aware about the existence and the possibility of treatment, or perhaps the referral of the patient to their peer specialists. ${ }^{(2)}$ Bullous diseases based on their clinical appearance in the oral cavity are implantable diseases for the dentist, as it is emphasized the fact that intraoral examination may also be required for extracorporeal surgery, and in addition to the strong stomach (teeth), the intracranial soft structures, a well-behaved eye about the clinical appearance of soft tissue lesions. Bullous diseases affect men and women more often than menopause, as the systemic flow of menopause with its decreases and elevations promotes clinical expression of these diseases. Receiving data in hospitalized patients and in outpatients helps in comparing the patient's views with these diseases and at the dentist's view on patient access. ${ }^{(3)}$ Each patient involved in the study is well-informed, and then has been agreed upon in full consensus on the condition of the patient, became part of the study, and then proceeded with the established protocol.

\section{Materials and methods}

The study includes patients randomly presented at the University Clinic AU and patients in the Department of Dermatology, QSUT, time periods between November 2017 and January 2018. The patients of the first group included in the study, were patients presented $a d$-hock at the University Clinic for periodontal treatment during the period between November and January 2017-2018. All involved patients were informed about the protocol and duration of the procedure, the obligation to answer some questions, to examine and photograph in case of 
evidence of a lesson in oral cavity. This protocol was also clarified with patients, carried out only for the effect of the study, the patient would be kept anonymous, and in case of indication would be referred for further examinations. Of the total of 400 patients, 89 of them refused to take part in the study. $78 \%$ of respondents gave their consent to become a part of the study, some of them (female gender) despite having been provided with the anonymity, were not ready to present to others the sensation or symptoms they would questioned. Every patient involved in the study is well informed, and then the consensus is fully consensus to become part of the study, and then proceed with the established protocol. The response to the questionnaire, Dermatological Life Quality Index (ICJD), was also a part of taking the history. ${ }^{(6,20)}$ The index consists of 10 questions that the patient can answer in 5 different ways. The objective of this questionnaire is to see how the skin problems last week affected the life of the patient. The answers are evaluated with the following points: many 3 points, 2 points, 1 point and not at all, and 0 points.

The questionnaire is finally evaluated with a total score of 10 questions, as follows:

$0-1=$ no effect in the patient's life,

$2-5=$ minimal effect on patient's life,

6-10 = moderate effect on patient's life,

11-20 = significant effect on patient's life,

21-30 = very high effect on patient's life.

Results can also be translated into percentages eg, 3, 6 .

Subsequently, patients underwent oral mucous membrane and gingival examination. Every lesion or pathology was recorded. Patients were required to be photographed in the lesson to be documented for further examinations. Patients of the second group are patients who, with the help of the dermatologist and with their consent, were only subjected to visual examination of skin lesions. Patients of this group were patients in the Department of Dermatology QSUT Tirana, during the same period above the first group patients (November-January 20172018).

Continuous data were presented in average and standard deviation, while discrete data were presented in absolute value and in percentage. Graphs and tables of various types (simple and complex) were used to present the data. $P$ values smaller than 0.05 were considered statically important. The statistical analysis was carried out mainly through the SPSS version 15 program and partly through the MS Excel program.

\section{Results}

After collecting the data in the base table of excellence, they were processed for purpose of displaying the results of the study according to the tables below.

Table 1. This table shows the availability of patients according to the male:female ratio, to be included in the study where they could divide life-quality components based on the dermatologically selected index.

\begin{tabular}{|c|c|c|c|c|}
\hline Patiets & Included & \% of inclusion & Not included & \% of non-inclusion \\
\hline Female & 175 & $56 \%$ & 62 & $70 \%$ \\
\hline Male & 136 & $44 \%$ & 27 & $30 \%$ \\
\hline Total & 311 & $100 \%$ & 89 & $100 \%$ \\
\hline
\end{tabular}

The average age of female patients was 43 years and the average age of male patients was 45 years (the patient involved in the study).

Graph 1. The graph shows the data on the inclusion of patients according to the female male ratio, to the registration of the Dermatological Life Quality Index. 


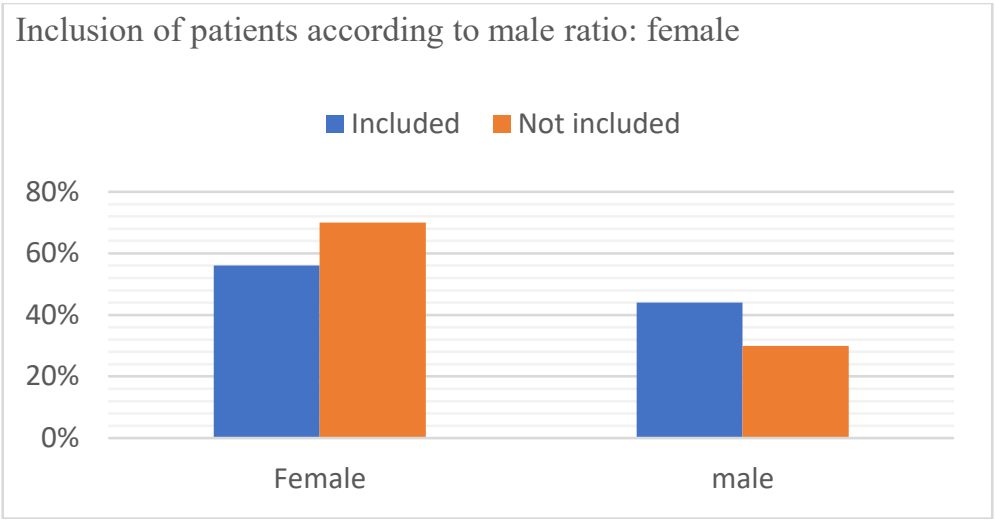

Table 2. Separation of patients by age and area of lesion - female, male patients.

\begin{tabular}{|c|c|c|c|c|c|c|}
\hline $\begin{array}{c}\text { Female } \\
\text { Patients }\end{array}$ & $\begin{array}{c}\text { Lesions in } \\
\text { mucosa }\end{array}$ & $\%$ & Lesions in gingiva & $\%$ & $\begin{array}{c}\text { Lesions in gingiva } \\
\text { and oral mucosa }\end{array}$ & $\%$ \\
\hline$\leq 39$ vjeç & 4 & $21 \%$ & 0 & $0 \%$ & 0 & $0 \%$ \\
\hline$\geq 40$ vjeç & 8 & $42 \%$ & 4 & $21 \%$ & 3 & $16 \%$ \\
\hline Totali & 12 & $63 \%$ & 4 & $21 \%$ & 3 & $16 \%$ \\
\hline
\end{tabular}

\begin{tabular}{|c|c|c|c|c|c|c|}
\hline $\begin{array}{c}\text { Male } \\
\text { patients }\end{array}$ & $\begin{array}{c}\text { Lesions in } \\
\text { mucosa }\end{array}$ & $\%$ & Lesions in mucosa & $\%$ & $\begin{array}{c}\text { Lesions in gingiva } \\
\text { and oral mucosa }\end{array}$ & $\%$ \\
\hline$\leq 39$ vjeç & 0 & $0 \%$ & 2 & $29 \%$ & 0 & $0 \%$ \\
\hline$\geq 40$ vjeç & 1 & $14 \%$ & 4 & $57 \%$ & 0 & $0 \%$ \\
\hline Totali & 1 & $14 \%$ & 6 & $86 \%$ & 0 & $0 \%$ \\
\hline
\end{tabular}

Figure 2. The graph shows the age-specific and lesion-specific patients - female patients / male patients.

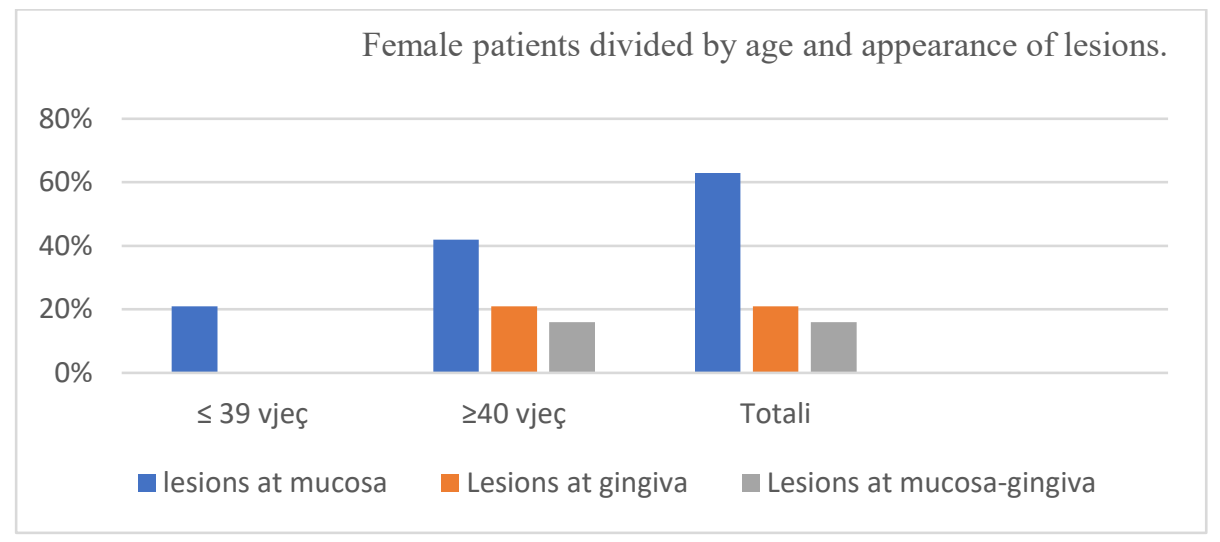




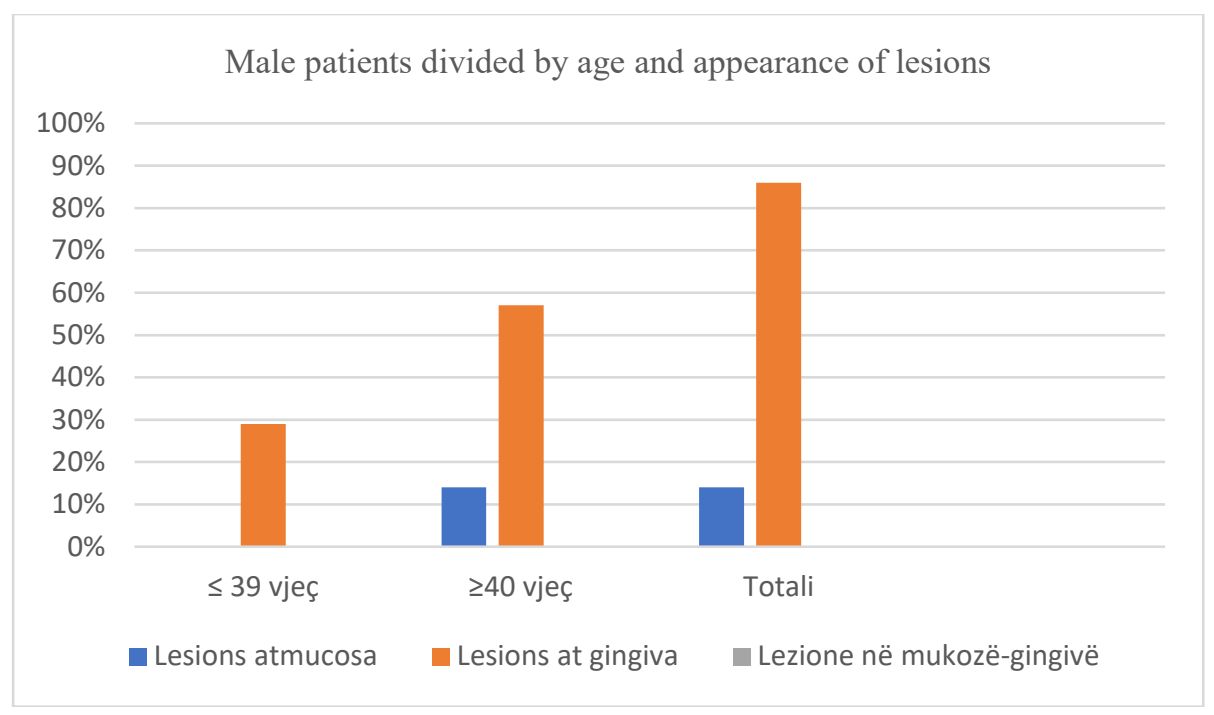

Table 4. The table presents the prevalence of dermatological disease by age in female and male patients by age limit -40 years.

\begin{tabular}{|c|c|c|c|c|}
\hline Patients & Female & \% & Male & \% \\
\hline$\leq 39$ vjeç & 4 & $15 \%$ & 2 & $8 \%$ \\
\hline$\geq 40$ vjeç & 15 & $58 \%$ & 5 & $19 \%$ \\
\hline Total & 19 & $73 \%$ & 7 & $27 \%$ \\
\hline
\end{tabular}

Graph 4. The graph shows the prevalence of dermatological disease, by sex and age.

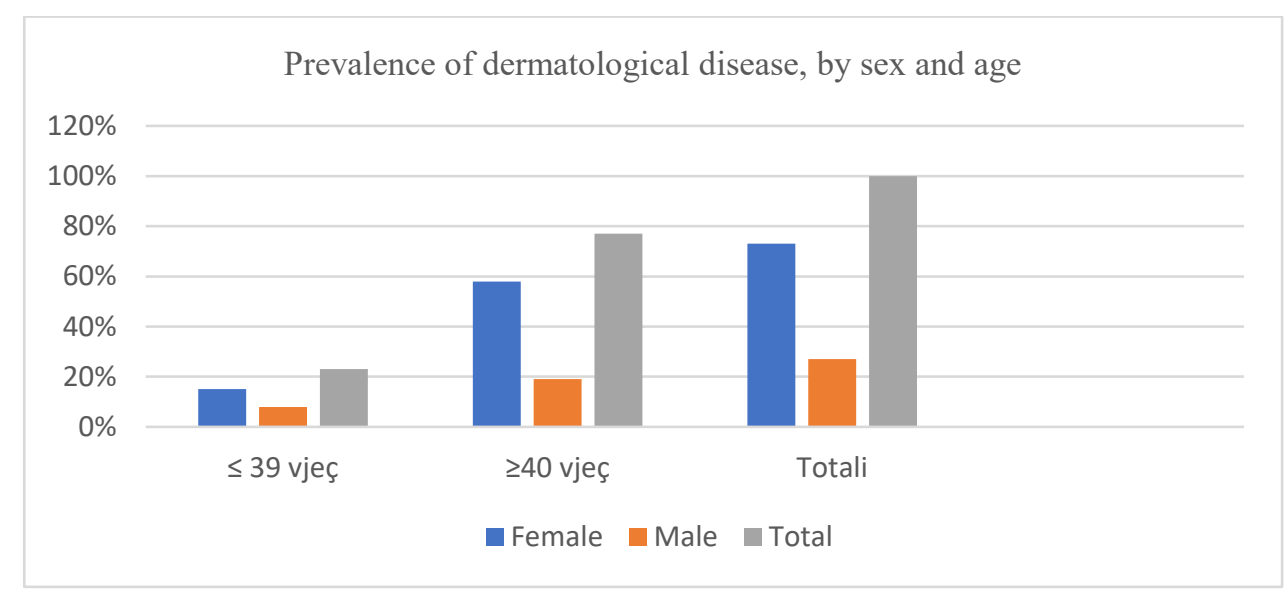

Table 5. The table presents the data collected from the Dermatological Quality Index, according to the subsection below.

$0-1=$ no effect in the patient's life

$2-5=$ minimal effect on patient's life

6-10 = moderate effect on patient's life

11-20 $=$ Significant effect on patient's life

21-30 $=$ very high effect on patient's life. 


\begin{tabular}{|c|c|c|c|c|}
\hline $\begin{array}{c}\text { Total at point of } \\
\text { reply }\end{array}$ & Female & \% & Male & $\%$ \\
\hline $\mathbf{0 - 1}$ & 0 & $0 \%$ & 0 & $0 \%$ \\
\hline $\mathbf{2 - 5}$ & 16 & $9 \%$ & 4 & $2 \%$ \\
\hline $\mathbf{6 - 1 0}$ & 3 & $2 \%$ & 3 & $1.7 \%$ \\
\hline $\mathbf{1 1 - 2 0}$ & 0 & $0 \%$ & 0 & $0 \%$ \\
\hline $\mathbf{2 1 - 3 0}$ & 0 & $0 \%$ & 0 & $0 \%$ \\
\hline Total & 19 & $11 \%$ & 0 & $3.7 \%$ \\
\hline
\end{tabular}

The following figures give clinical cases presented to the Clinic.

Fig. 1. This figure shows oral lesions in a female patient under the age of 39.
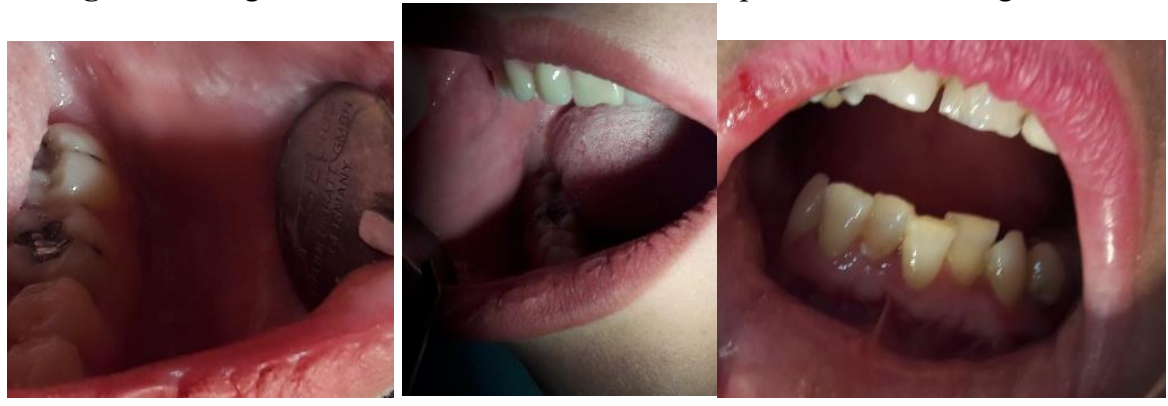

Fig. 2. A female patient with site lesions in the ulcer, posterior region and hypersensitivity of the other side is shown in this figure.

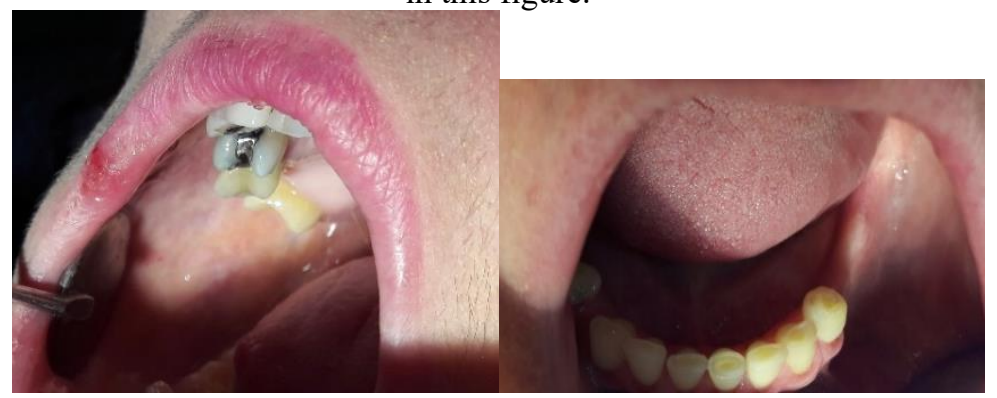

Fig. 3. Male patients with initial lesions of gingivitis defective in the area of the incisors and maxillary mandibular molar-premolars.

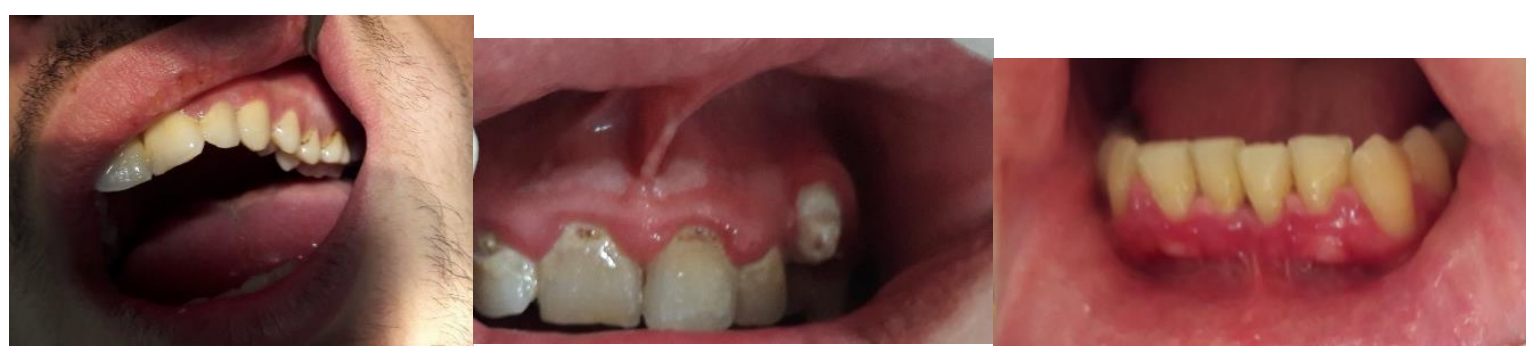


Fig. 4. Patients with generalized dermatological lesions, posed in the Department of Dermatology, QSUT.

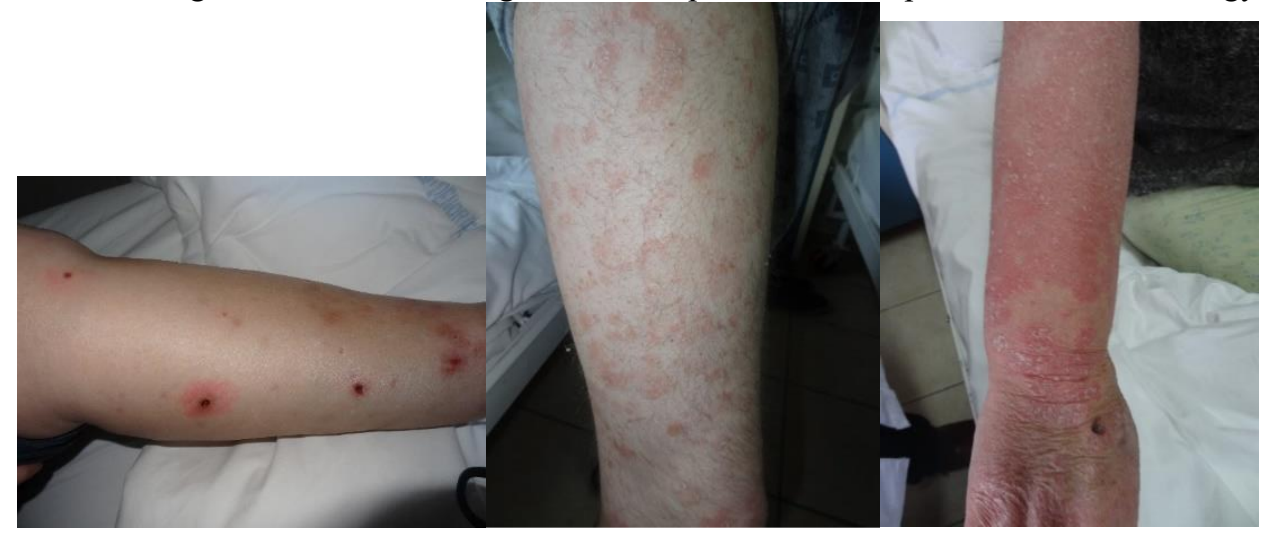

\section{Discussion}

Patient availability data to be included in the study, from literature data can be said that there are already many registered studies in well-informed and recorded dental students during the cycle of studies, about patients involved in different studies. The difficulty lies in the fact that the student is questioning the patient and this is what the latter puts, because the student pretends to learn, instruct the patient about oral hygiene, or dental problems, or is the student who claims to help patient with the goal of removing dental anxiety. This is the key to the inner conflict that occurs in the patient, in answering if he/she wants to include in the questionnaire where the patient will share personal information elements that are important to the patient.

Another element of the difficulty lies in the fact that the student should also explain how the questionnaire meets. In some cases, even a member of a medical staff should be present, as questioners may have difficulty in understanding how they should be fulfilled. This is the reason why the questionnaires can be filled out by the patients themselves, or they must be filled in with the presence of a dental student or a staff member. Sometimes, it is good for students to be offered the personal experience of the medical staff member when he or she is a patient or student to experience the patient's experience of understanding the patient's doubts in the decision whether to include the questionnaire or not. Absolutely volunteer patient should be a patient willing to help students in acquiring communication skills. There should be no limits and selection criteria for volunteer involvement of patients in studies, widespread volunteer variety, enhanced student experience, experience gained and assimilated, and more positive feedback. ${ }^{(25)}$

In support of published literature on clinical and pathological relationships of various oral lesions, a non-compliance ranges from 17 to $42 \%$. Still, in this literature, this discrepancy in the clinical and pathological correlations of oral lesions depends on different factors, selected from predetermined histopathological areas, total patient samples as percentages and patient types varied between studies. This inconsistency also depends on the subjective variations of the clinician and the histopathologist. There is a need for strict clinical and histological criteria for establishing the diagnosis. In the case of our study, in view of the difficulties encountered in the diagnosis and treatment of dermatological diseases of autoimmune origin in our country, the imposition of these criteria was difficult. ${ }^{(15,18)}$ From the variety of dermatological diseases of autoimmune origin, was only pemphigus is chosen with all its types, not the point of diagnosis of various types of clinic of this disease, but only to identify, within the possibilities, endangered individuals. In the results of our study were included exclusionary criteria, all patients who were positive to Kobner's symptom. This is to exclude patients prone to dermatological diseases, not the appearance of gingivitis in the oral cavity.

Based on the research in literature, pemphigus vulgaris reflects a total susceptibility of $12.5 \%$, for example with lichen planus in $37.5 \%$ or leukoplakin with $20 \%$ susceptibility. ${ }^{(23)}$ Backed up to this source of literature in patients with lichen planus male ratio: female was $43.3 \%$ with $56.6 \%$, for leukoplakin was $60 \%$ with $40 \%$ and for pemphigus vulgaris was $60 \%$ at $40 \%$. For lupus erythematosus the patient's vulnerability to this disease was $12.5 \%$ divided by gender by $30 \%$ with $70 \%$. In the case of our study, the susceptibility to male ratio: female was $27 \%$ at $73 \%$. Further, the purpose of the study was the age effect on the appearance of dermatological disorders of patients. The age limit set in our study is 40 years of age. Lessons and dermatological problems encountered before the age of 40 , or after the age of 40 years. This age limit was only based on fact that this age serves as the limit of starting the initial menopause signs. It is known that sensitive fluctuations in sex hormone levels have a significant effect on 
sensitive fluctuations in the female body, immune response rates, and the susceptibility of the organism to dermatological diseases of autoimmune origin. By comparing the age levels of oral lesions in the oral cavity for autoimmune diseases, in relation to local risk factors, it can be said that the largest number of patients with lichen planus, lupus erythematosus and pemphigus vulgaris ranged from 31 to 45 years and leukoplakis lesions, the age of patients varies from 46 to 60 years. If we talk about the average age of patients affected by these diseases specifically for lupus is 38 years old with standard deviation 14.62, for lichen planus is 39.6 years with a standard deviation of 14.62 , for pemphigus vulgaris the average age is 38 years with a standard deviation of $11.73 . .^{(22,24)}$ In our study, the average age of female patients was 43 years and the average age of male patients was 45 . $^{(25)}$ In our study, the average age of the patients was 45 years and the average age of the patients was 45.(25) Only gingivitis lesions can occur, but can also occur in mucosal lesions, or in both areas at the same time. Moreover, when we talk about pemphigus, when it is necessary that the lesion's laboratory analysis be confirmed with direct immunofosforism and reconfirmed with indirect immunofosforce. Both analyzes should be positive to confirm the safe presence of the disease. Analysis that is costly for the patient, but when performed in the right time prevents the disease, when the treatment begins in the right time. Advice for dental professionals includes some of the following: A complete oral mucous examination should be performed, evaluating for any anomalies, including complications in the oral cavity of pemphigus or pemphigoid treatment, such as candidosis, so everyone needs to be careful about maintenance schedules and set more frequent schedules to control the gravity and progression of the disease. ${ }^{(1,2)(5,7-11)}$ Nisengard and Levine ${ }^{(10)}$ cited as standard in establishing clinical diagnosis of gingivitis, chronic rash, ulceration, and/or bubble formation. Gingivitis deskuamtiv: (1) presence of gingival erythema that does not result from the plaque, (2) gingivitis, (3) other intraoral lesions and sometimes extra, sore mouth complaints, especially in case of application of aromatic foods. It is reported that most cases of dysfunctional gingivitis are caused by some mucocutaneous diseases. ${ }^{(5,7-9)}$ In our study, the initial signs of dysfunctional gingivitis are present in 7 patients, but all of these in lighter clinical signs.

Pemphigoid mucosal membrane and lichen planus erosive are the most common causes of dysfunctional gingivitis, respectively $48.9 \%$ and $23.6 \%$ of all cases of dysfunctional gingivitis. ${ }^{(8)}$ In our patients there were no pruritus signs in the skin of the back or on the dorsal surfaces of the arms and legs, which removed the clinical diagnosis of pemphigus vulgaris from the lichen planus. In the patients involved in the study, there were no sign of symblepharon, a clinical sign that removed the clinical diagnosis from pemphigoid. Histopathological examination and direct immunofluorescence testing are necessary to establish the ultimate diagnosis of diseases responsible for the defective gingivitis. ${ }^{(5,7,9-11)}$ Given that pemphigus vulgaris is potentially fatal, the recognition of gingival lesions of gingivitis desquaming, though rare, is essential for ultimate diagnosis, timely therapy, and patient follow-up. There are cases where it is needed for more than 1 year until the final diagnosis of pemphigus vulgaris ${ }^{(25)}$, which is measured after the patient's appearance in the dental unit, with primary signs of oral cavity. During this period, the patient visited a dental clinic, an otolaryngology clinic and an internal medicine clinic, but no final diagnosis was provided at any of these clinics. Reasons for delayed diagnosis may be explained by the fact that the symptoms of pemphigus vulgaris of the patient are limited to the gingiva and are clinically very light and by the fact that the symptoms occur in repeated cycles of healing and deterioration.

For the final diagnosis of pemphigus vulgaris, the following criteria must be met: (1) the presence of relevant clinical lesions, (2) confirmation of acantholysis in biopsy specimens, and (3) autoantibody confirmation in tissue or serum, or both. In the present case, a final diagnosis of pemphigus vulgaris was made based on a general assessment of the following findings: (1) positive phenomenon of Nikolsk, (2) presence of acantholysis in biopsy specimens, and (3) locating deposition of antibodies between epithelial cells with direct immunofluorescence test. All patients involved in the study are recommended for further visits to dermatologists, as establishing a diagnosis for pemphigus is a multidisciplinary decision in terms of treatment and diagnosis for such diseases in our country.

\section{Conclusions}

The documented data showed the presence of initial signs of gingivitis desquamative, clinical signs that should be checked and carefully examined by dental specialists as they are the first to contact the patient suffering from these symptoms.

Dermatological diseases of autoimmune origin, classified as vesiculobulose diseases, are encountered in the gingiva, in the mucous membranes, or in the gingiva and in the mucous membranes. For female patients, tachycardia appears more frequently in the lining of the mucous membrane, while for male patients, tachycardia appears more frequently with gingival lesions. The fact that women are most affected by autoimmune bulous lesions and higher predisposition have been confirmed by women over the age of 40 . The impact of the skin on the patient's difficulties during the day- 
to-day activity is more pronounced in female patients than in male patients, which is based on the Dermatological Life Quality Index assessment, applied in our study.

Acknowledgments: Our thanks belong to our family. Henri and Hera drive us forward, and further in the field of scientific research.

Author Contributions: Literature research was conducted by Dr. Saimir Heta. It was his insistent work that made it possible to reach the conclusions in this article.

Conflicts of Interest: We declare that there is no conflict of interest between the authors and the material presented in this article.

\section{Referenca}

1. Stanley, John R. (2003). "Chapter 59: Pemphigus". In Freedberg; et al. Fitzpatrick's Dermatology in General Medicine (6th ed.). McGraw-Hill. p. 559. ISBN 0-07-138067-1.

2. https://media.gettyimages.com/photos/pemphigus-vulgaris-an-autoimmune-intraepithelial-blisteringdisease-picture-id128575331).

3. http://www.ijdvl.com/articles/2015/81/6/images/ijdvl_2015_81_6_655_168342_f1.jpg.

4. Irwin M. Freedberg; et al., eds. (2003). Fitzpatrick's dermatology in general medicine (6th ed.). New York, NY [u.a.]: McGraw-Hill. p. 558. ISBN 0-07-138076-0.

5. International Journal of Women's Dermatology; Volume 1, Issue 1, February 2015, Pages 4-12.

6. Cathy Y.ZhaoMBBS, MMedDédée F.MurrellMA, BMBCh, FACD, FAAD, FRCP, MD; "Autoimmune blistering diseases in females: a review"; Int J Womens Dermatol. 2015 Feb; 1(1): 4-12.; Published online 2015 Feb 26. doi: 10.1016/j.jijwd.2015.01.002.

7. Theofilopoulos AN. The basis of autoimmunity: Part I: Mechanisms of aberrant self-recognition. Immunol Today. 1995;16:90-97. [PubMed]

8. Aoki $\mathrm{V}^{1}$, Rivitti EA, Diaz LA; "Update on fogo selvagem, an endemic form of pemphigus foliaceus.; Cooperative Group on Fogo Selvagem Research"; J Dermatol. 2015 Jan;42(1):18-26. doi: 10.1111/13468138.12675 .

9. Carranza - Clinical periodontology; Mosby 2009; Kapitulli Gingiviti Deskuamativ.

10. Kim D. Edhegard, Russell P. Hall, in Clinical Immunology (Fourth Edition), 2013.

11. Hashimoto T, Teye K, Ishii N. Clinical and immunological studies of 49 cases of various types of intercellular IgA dermatosis and 13 cases of classical subcorneal pustular dermatosis examined at Kurume University. $\mathrm{Br}$ J Dermatol 2017; 176:168.

12. J Am Acad Dermatol. 1990 May;22(5 Pt 2):917-9. Intraepidermal neutrophilic IgA dermatosis. Kuan $\mathrm{YZ}^{1}$, Chiou HT, Chang HC, Chan HL, Kuo TT. Dermatology 1992;185:311-313.

13. Gengoux P. · Tennstedt D. - Lachapelle J.M.; Intraepidermal Neutrophilic IgA Dermatosis: Pemphigus-Like IgA Deposits; Unit of Occupational and Environmental Dermatology, Louvain University, Brussels, Belgium; Dermatology 1992;185:311-313; (DOI:10.1159/000247480).

14. Korman $\mathrm{NJ}^{1}$, Eyre RW, Zone J, Stanley JR. Drug-induced pemphigus: autoantibodies directed against the pemphigus antigen complexes are present in penicillamine and captopril-induced pemphigus. $J$ Invest Dermatol. 1991 Feb;96(2):273-6.

15. Landau $\mathrm{M}^{1}$, Brenner S. Histopathologic findings in drug-induced pemphigus. Am J Dermatopathol. 1997 Aug;19(4):411-4.

16. https://www.mayoclinic.org/-/media/kcms/gbs/patientconsumer/images/2013/08/26/10/29/ds00749_im01954_r7_pemphigusfoliaceusthu_jpg.jpg.

17. https://www.mayoclinic.org/-/media/kcms/gbs/patientconsumer/images/2013/08/26/10/05/ds00749_im00813_ans7_pemphigusthu_jpg.jpg.

18. Ferri FF. Pemphigus vulgaris. In: Ferri FF, ed. Ferri's Clinical Advisor 2016. Philadelphia, PA: Elsevier; 2016:941-942.

19. Habif TP. Vesicular and bullous diseases. In: Habif TP, ed. Clinical Dermatology. 6th ed. Philadelphia, PA: Elsevier; 2016:chap 16.

20. Finlay AY, Khan GK. "The Dermatology Life Quality Index: A simple practical measure for routine clinical use". British Association of Dermatologists Annual Meeting, Oxford, July 1993. British Journal of Dermatology, 1993; 129 (Suppl 42): 27. 
21. Finlay AY, Khan GK. "The Dermatology Life Quality Index: A simple practical measure for routine clinical use". British Association of Dermatologists Annual Meeting, Oxford, July 1993. British Journal of Dermatology, 1993; 129 (Suppl 42): 27.

22. Finlay AY, Khan GK. Dermatology Life Quality Index (DLQI) - a simple practical measure for routine clinical use. Clinical and Experimental Dermatology, 1994; 19: 210-216.

23. Anstey A, Reynolds NJ. "What does the BJD now stand for? A position statement". British Journal of Dermatology 2015; 172: 1463-1465.

24. World Health Organisation. Global report on psoriasis. ISBN 978924156518 9. WHO Press, Geneva, 2016, p16.

25. https://www.google.com/url;health.adelaide.edu.auFvolunteer-patient-program. 